\title{
Effectiveness of different final irrigation techniques and placement of endodontic sealer into dentinal tubules
}

\section{Kauhanna Vianna de OLIVEIRA ${ }^{\text {(a) }}$ Bruno Marques da SILVA(a) Denise Piotto LEONARDI(a) Bruno Monguilhott CROZETA ${ }^{(b)}$ Manoel Damião de SOUSA-NETO(b) Flares BARATTO-FILHO(a) Marilisa Carneiro Leão GABARDO(a)}

(a) Universidade Positivo, Department of Dentistry, Curitiba, PR, Brazil.

(b) Universidade de São Paulo - USP, School of Dentistry of Ribeirão Preto, Department of Dentistry, Ribeirão Preto, SP, Brazil.

Declaration of Interests: The authors certify that they have no commercial or associative interest that represents a conflict of interest in connection with the manuscript.

\section{Corresponding Author:}

Flares Baratto-Filho

E-mail: fbaratto1@gmail.com

https://doi.org/10.1590/1807-3107BOR-2017.vol31.0114

Submitted: Aug 08, 2017

Accepted for publication: Nov 11, 2017

Last revision: Nov 23, 2017
Abstract: The aim of this study was to compare two irrigation techniques and four devices for endodontic sealer placement into the dentinal tubules. Ninety-nine single-rooted human teeth were instrumented and allocated to either the control $(\mathrm{CO})(\mathrm{n}=11)$ or experimental groups according to the irrigation method: syringe and NaveTip needle (NT) $(n=44)$, and EndoActivator (EA) $(n=44)$. These groups were subdivided according to sealer placement into K-File (KF), lentulo spiral (LS), Easy Clean (EC), and EndoActivator (EA) subgroups. Moreover, the distances of $5 \mathrm{~mm}$ and $2 \mathrm{~mm}$ from the apex were analyzed. The teeth were obturated with AH Plus and GuttaCore X3. Analyses were performed by scanning electron microscopy associated to cathodoluminescence. The percentage and maximum depth of sealer penetration were measured. Data were evaluated by three-way analysis of variance (ANOVA) and Games-Howell test $(\mathrm{p}<0.05)$. EA was superior to NT in percentage of sealer penetration. EC was significantly superior to EA (subgroup) for sealer penetration, and both improved the percentage of sealer penetration when compared to LS. Better sealer penetration was observed at the distance of $5 \mathrm{~mm}$ from the apex. Sealer penetration into the dentinal tubules was significantly improved by sonic irrigant activation.

Keywords: Microscopy, Electron, Scanning; Canals Sealer

\section{Introduction}

The main purpose of endodontic treatment is to control infections and prevent reinfections. ${ }^{1}$ However, the complex anatomy of root canal systems might render disinfection difficult in specific ramifications and dentinal tubules, especially in the apical third. ${ }^{2}$

Root canal preparation and shaping is an important step in decreasing endodontic contamination. Moreover, irrigants as sodium hypochlorite $(\mathrm{NaOCl})$ and ethylenediamine tetraacetic acid (EDTA) can penetrate mechanically inaccessible areas, dissolving organic tissues and removing smear layers, ${ }^{3}$ and are indispensable in the apical third. ${ }^{4,5}$ Finally, endodontic sealers have antibacterial properties and their full potential is achieved when placed in direct contact with clean and prepared root canal walls; the penetration of sealers in the dentinal tubules also improve the seal and the obturation quality. 
The effective placement of a canal sealer depends on the anatomic features of the canal besides the canal shaping process. ${ }^{2}$ The instruments and materials described in the literature for this purpose are guttapercha cones, paper points, Lentulo spirals, K-files, and ultrasonic files. $7,8,9$

Endodontic sealer penetration has been analyzed by confocal laser scanning microscopy (CLSM), which enables the visualization of deep structures of the optical sections, ${ }^{10}$ and the application of fluorescent dyes. ${ }^{11}$ Another method that has been used is the scanning electron microscopy (SEM), which allows superficial visualization of the dentinal tubules at high magnifications and resolutions; ${ }^{12}$ moreover, cathodoluminescence may be applied for sealer analysis.

Sonic devices are used for cleaning the canal; however, the association between irrigation techniques and sealer placement devices has not been evaluated by previous studies. The aim of this study was to evaluate the percentage and maximum depth of sealer penetration in vitro using SEM and cathodoluminescence. Two irrigation protocols and four sealer placement techniques were used with GuttaCore X3 obturation.

\section{Methodology}

\section{Sample selection}

After approval of the Research Ethics Committee (no. 1.732.357), 99 recently extracted human teeth with single canals (incisors, canines, and premolars), and anatomic diameter of the \#15 or \#20 K-file (Dentsply Maillefer, Ballaigues, Switzerland) at $0.1 \mathrm{~mm}$ from the apex, were selected.

\section{Root canal preparation}

A single operator performed all experimental procedures. The canals were prepared by Protaper Next system (Dentsply Maillefer, Ballaigues, Switzerland) X1 $(0,17.04), X 2(0,25.06)$, and X3 (0, $30.07)$, according to the manufacturer's instructions. The canals were irrigated using a syringe (Ultradent, South Jordan, USA) between the use of each file. The syringes contained $4 \mathrm{~mL}$ of $5.25 \%$ sodium hypochlorite $(\mathrm{NaOCl})$, and saline solution for control.

\section{Final irrigation}

The teeth were allocated according to the dental group and apical size at the time of final irrigation into three groups: conventional with syringe and NaveTip needle (Ultradent, South Jordan, USA) (NT) $(n=44)$, sonic with EndoActivator (Dentsply Maillefer, Ballaigues, Switzerland) (EA) $(n=44)$, and control (CO) $(n=11)$. In the NT group, $3 \mathrm{~mL}$ of $17 \%$ EDTA and $3 \mathrm{~mL}$ of $5.25 \% \mathrm{NaOCl}$ were used to rinse the canal using $5 \mathrm{~mL}$ syringes with 30 -gauge side-vented needles. Each irrigant was used for one minute and placed into the canal $1 \mathrm{~mm}$ short of the working length. In the EA group, the same irrigants were used for the same time and length, however, the \#25.04 EndoActivator tip (red) was used. In the $\mathrm{CO}$ group, the same protocol as that of the NT group was applied using saline solution.

\section{Sealer placement}

AH Plus sealer $(0.05 \mathrm{~mL}$ ) (De Trey, Konstanz, Germany) was introduced into the canals with a tuberculin syringe. At this stage, the teeth irrigated with NT and EA were divided according to the sealer placement devices used in the groups $(n=11$ in each) as follows:

NT + K-File (NTKF): the sealer was placed into the canal by counterclockwise rotation using \#25.02 K-file (Dentsply Maillefer, Ballaigues, Switzerland);

NT + Lentulo spiral (NTLS): a \#25.02 Lentulo spiral (Dentsply Maillefer, Ballaigues, Switzerland) was attached to a handpiece at $20.000 \mathrm{rpm}$.

NT + Easy Clean (NTEC): a \#25.04 plastic tip (Easy Equipamentos Odontológicos, Brazil) was attached to a handpiece at $20.000 \mathrm{rpm}$.

NT + EndoActivator (NTEA): the sealer was placed into the canal using a \#25.04 tip.

The same group division was done with the other teeth, but using EA irrigation, forming the following subgroups ( $\mathrm{n}=11)$ : EAKF, EALS, EAEC, and EAEA.

Each group was analyzed at $5 \mathrm{~mm}$ and $2 \mathrm{~mm}$ distances; the groups were finally named: NTKF5, NTLS5, NTEC5, NTEA5, EAKF5, EALS5, EAEC5, EAEA5, NTKF2, NTLS2, NTEC2, NTEA2, EAKF2, EALS2, EAEC2, and EAEA2. 


\section{Root canal obturation and storage}

The canals were obturated with GuttaCore X3 obturator, heated in a ThermaPrep oven (Dentsply Maillefer, Ballaigues, Switzerland), following the manufacturer's instructions. Excess gutta-percha and sealer was removed at the level of the cementoenamel junction and soft vertical compaction was performed using a Schilder ${ }^{\circledR}$ plugger (Dentsply Maillefer, Ballaigues, Switzerland). Coronal access was sealed with Light-Cured Universal Restorative (Fuji II LC, GC Corporation, Japan). The teeth were then stored in an incubator at $37^{\circ} \mathrm{C}$ and $100 \%$ humidity for 24 hours.

\section{Rhodamine B isothiocyanate on AH Plus sealer (CLSM) analysis}

To determine the concentration of the fluorescent dye, a pilot study was done with $0.1 \%$ fluorescent rhodamine B isothiocyanate dye (Sigma-Aldrich, St Louis, USA).
Twelve biradicular premolars were selected and endodontically treated following the same protocol described previously. Rhodamine B isothiocyanate was weighed in milligrams with a precision scale. Five concentrations of dye and a sample without rhodamine were tested ( $\mathrm{n}=4$ in each group): 0.00 , $0.02,0.05,0.10,0.20$, and $0.30 \mathrm{mg} / \mathrm{mL}$. Each tooth was sectioned with a diamond disc, separating the crowns from the roots. Therefore, each concentration was tested in four samples.

The $0.3 \mathrm{mg} / \mathrm{mL}$ rhodamine/sealer concentration was more effective (Figure 1), and thus this concentration was added to the AH Plus before it was inserted into the canals.

\section{Teeth section (CLSM)}

Each tooth was sliced at $90^{\circ}$ to the long axis using a diamond blade in IsoMet (Buehler, Illinois, USA). Two samples of each tooth were obtained with $1 \mathrm{~mm}$
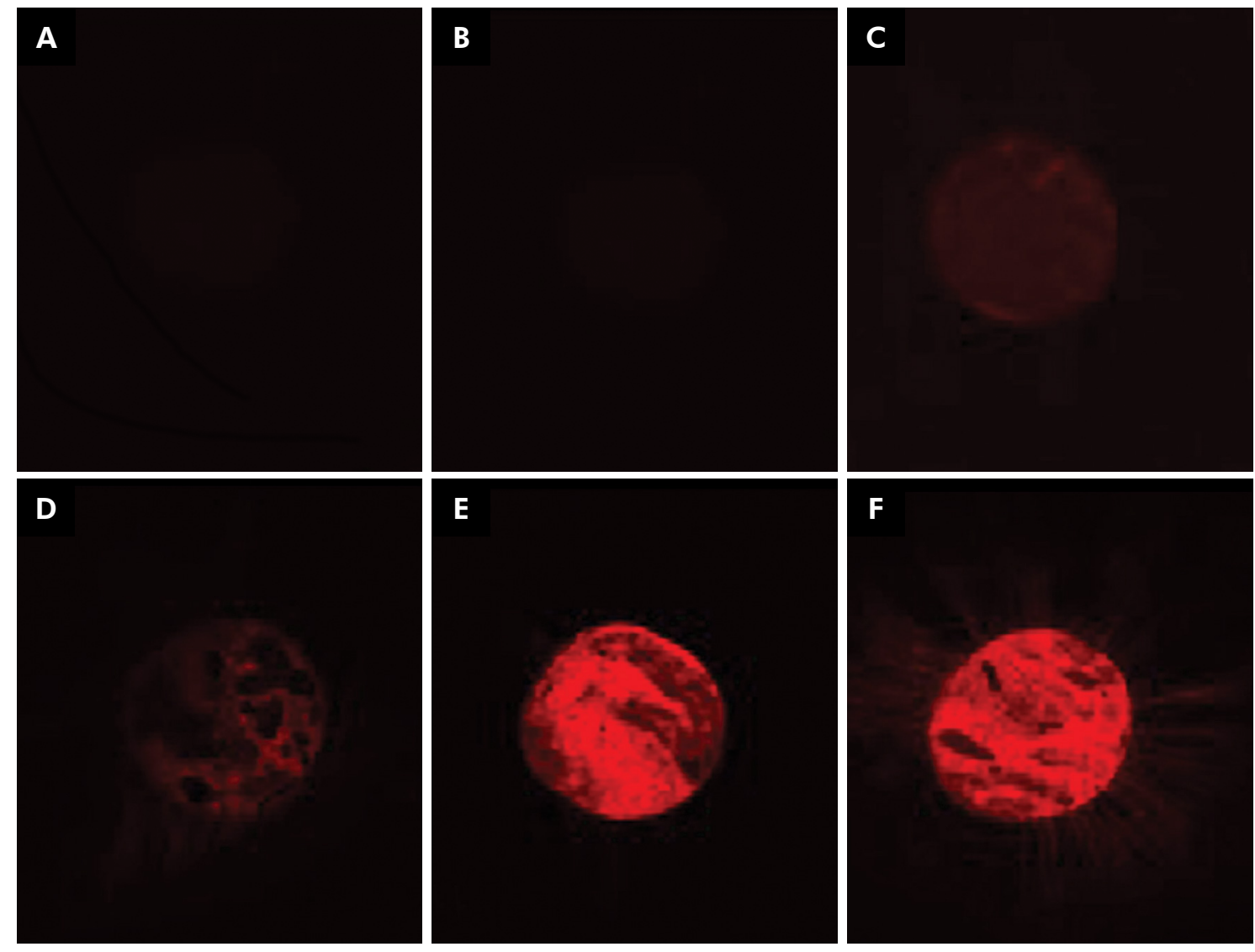

Figure 1. Concentrations of rhodamine $B$ isothiocyanate/sealer (A: $0.00 \mathrm{mg} / \mathrm{mL} ; \mathrm{B}: 0.02 \mathrm{mg} / \mathrm{mL} ; \mathrm{C}: 0.05 \mathrm{mg} / \mathrm{mL} ; \mathrm{D}: 0.10 \mathrm{mg} / \mathrm{mL}$; E: $0.20 \mathrm{mg} / \mathrm{mL} ; \mathrm{F}: 0.30 \mathrm{mg} / \mathrm{mL}$ ). 
thickness, at $2 \mathrm{~mm}$ and $5 \mathrm{~mm}$ distances from the apex. The coronal surfaces of the samples were polished using silicon carbide abrasive papers. To remove debris, the samples were submerged in 17\% EDTA for 2 minutes and then $2.5 \% \mathrm{NaOCl}$ for 2 minutes.

\section{Image acquisition (CLSM)}

The sections were imaged using the Eclipse Ti CLSM in resonance mode A1R+ (Nikon, Tokyo, Japan) at $20 \times$ magnification in large image mode. NIS-Elements AR imaging software (Nikon, Tokyo, Japan) was used to evaluate the sections by using a calibrated measuring tool.

\section{Teeth section (SEM)}

In SEM evaluation, 90 teeth were sliced at $90^{\circ}$ to the long axis, removing a $3 \mathrm{~mm}$ section from a distance of 2 and $5 \mathrm{~mm}$ from the apex. The samples were washed in distilled water with detergent and then vacuum-dried.

\section{Image acquisition (SEM)}

Both sides of the 180 slices were observed under JSM-6010LA (Jeol, Tokyo, Japan) with Centaurus detector for cathodoluminescence analysis at $30 \times$ magnification and electron beam acceleration of $20 \mathrm{kV}$.

\section{CLSM and SEM image analysis}

The circumferences of the root canal walls were first outlined and measured with ImageJ software (https://imagej.net/) in CLSM and SEM images. The maximum extent of sealer penetration was measured from the canal wall to the point of deepest penetration in the dentinal tubules. Areas along the canal walls in which the sealer had penetrated were outlined and measured independent of the distance. The area outlined by sealer penetration was quantified in pixels and divided by the total area along the canal to determine the percentage of sealer penetration. Only one tooth from each group was submitted to CLSM to illustrate the comparison between this technique and SEM (Figure 2).

\section{Statistical analysis}

Statistical analysis was performed with parametric tests and $p$-values $<0.05$ were considered significant. A three-way factorial analysis of variance (ANOVA) was applied for overall comparisons, and GamesHowell test was applied for pairwise comparisons.
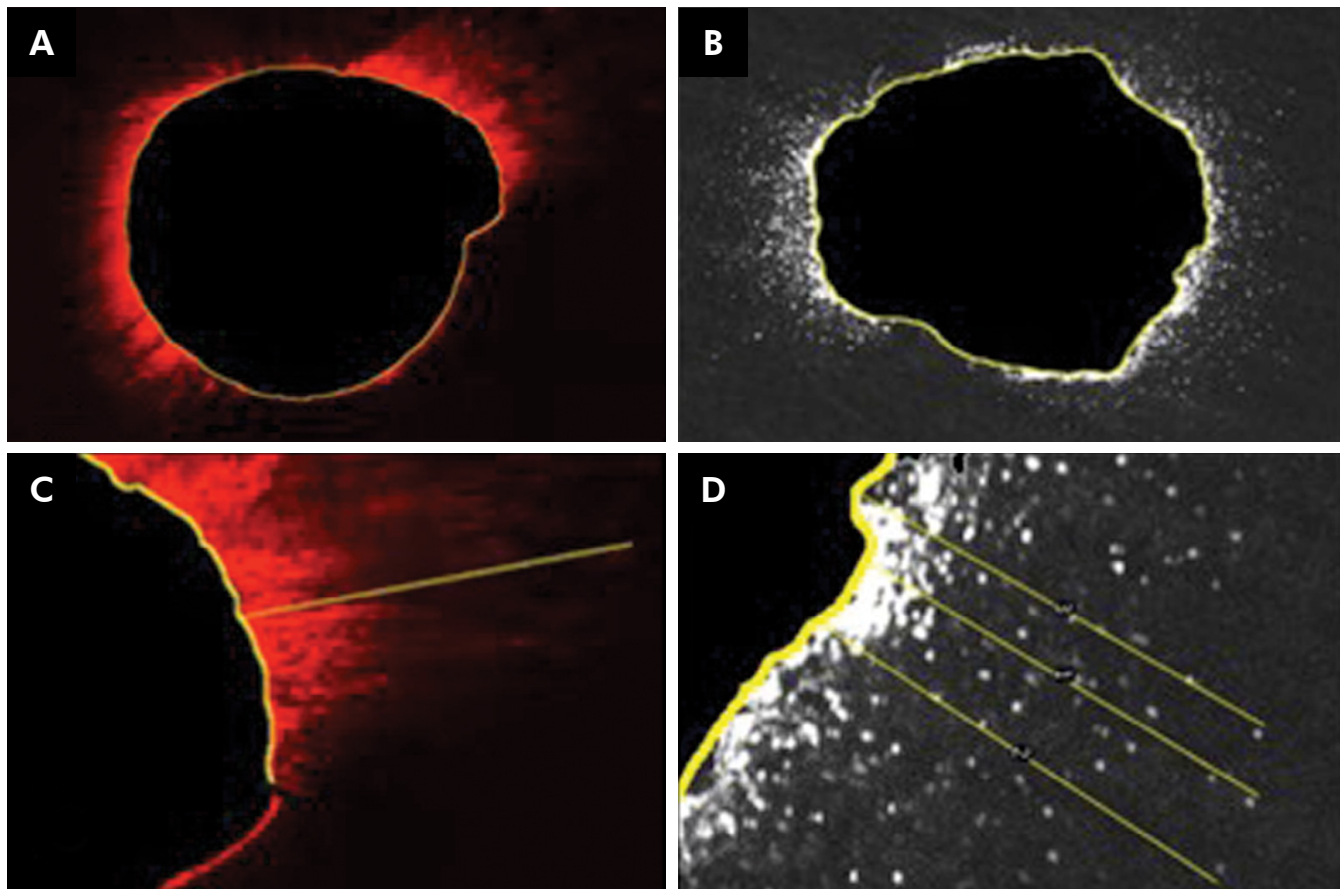

Figure 2. Images showing endodontic sealer penetration by CLSM (A) and SEM (B). Maximum depth of AH Plus dentinal tubule penetration by CLSM (C) and SEM (D).standard deviations are represented. 


\section{Results}

The percentage of sealer penetration and the maximum depth of sealer penetration for each group are presented as means and $95 \%$ confidence intervals (Figure 3). The 0.67 Pearson correlation coefficient was found between these variables.

\section{Percentage of sealer penetration}

The three-way ANOVA showed a significant difference $(p<0.05)$ and the Games-Howell post-test indicated that EA was better than NT, and both were higher than $\mathrm{CO}$, regardless of the instrument and the distance. The EC had better performance, followed by EA and LS. The area of sealer penetration was greater at the apical distance of $5 \mathrm{~mm}$ compared to $2 \mathrm{~mm}$, irrespective of the type of irrigation and instrument. When the factors irrigation technique, instrument, and apical distance were used in the analysis, there was no difference among NTKF5, NTLS2, NTEC5, NTEC2, NTEA5, EAKF5, EALS5, EAEC5, EAEC2, EAEA5, and EAEA2. There was no difference between the groups that had better performances ( $p>0.05$ ) (Figure 3 ).

\section{Maximum depth of sealer penetration}

Similarly, significant differences were found with the three-way ANOVA ( $p<0.05)$ and Games-
Howell post-test indicated that EA and NT were similar and had deeper sealer penetration than the $\mathrm{CO}$, regardless of the instrument and apical distance. EC was better than EA regardless of the irrigation and distance. As in the previous analysis, the apical distance of $5 \mathrm{~mm}$ had deeper penetration that $2 \mathrm{~mm}$ and was independent of the irrigation technique and instrument used. When all factors were considered (irrigation, instrument techniques, and apical distance), better results were obtained for the NTKF5, NTEC5, NTEA5, EAKF5, EALS5, EAEC5, EAEC2, and EAEA5 groups ( $p<0.05)$ (Figure 3$)$.

\section{Discussion}

Because of its antimicrobial spectrum and capacity to dissolve necrotic tissues, $\mathrm{NaOCl}$ is the most commonly used endodontic irrigant. After the final rinse, a chelating irrigant such as EDTA is also necessary. ${ }^{13}$ However, both solutions have limitations. ${ }^{14}$ Sonic and manual-dynamic activation during smear layer removal appeared to increase the effect of $\mathrm{NaOCl}$ and EDTA. ${ }^{4}$

Other studies showed no differences between sonic and conventional irrigation. ${ }^{15,16,17}$ The reason may be due to the small amount of irrigant that reaches the apical third, because sonic activation
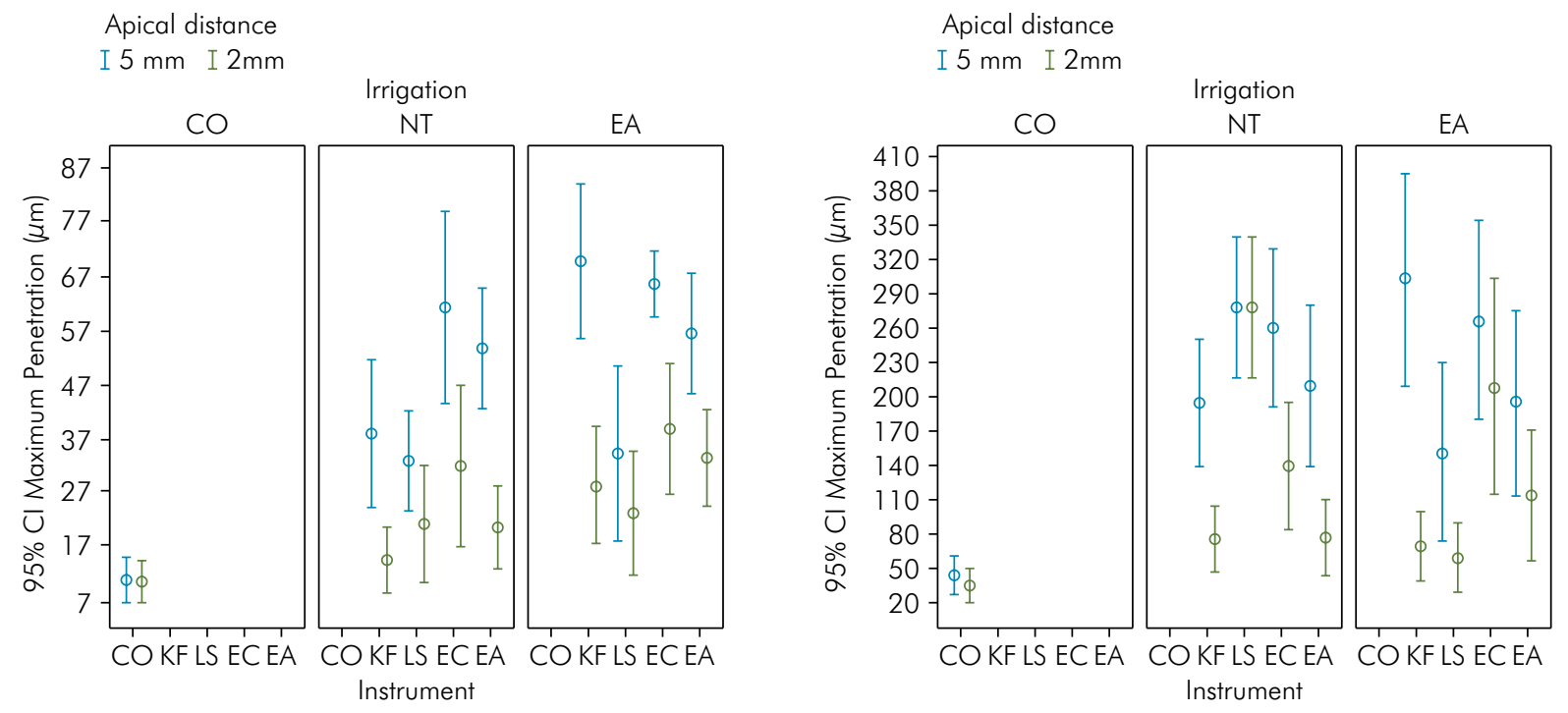

Figure 3. Graphics showing the percentage (A) and maximum depth (B) of endodontic sealer penetration. Means and standard deviations are represented. 
lasted for less than one minute. ${ }^{15,17}$ In addition, a low concentration of the solution could have caused the negative results. ${ }^{16}$ Another factor is the diameter of the needle, as smaller needles are desirable; thus, a 30-gauge needle was used in this study, as opposed to other studies, in which 25 -gauge needles were used to irrigate the canal of \#30 master apical size, according to $\mathrm{Gu}$ et al. ${ }^{18}$

The sealer penetrated the dentinal tubules that were unobstructed by smear layer. The sealer within the tubules prevents bacterial infection and reinfection. ${ }^{6}$ Physical and chemical properties of the AH Plus sealer confer optimal tubular penetration and adaption to the root canal wall. ${ }^{19}$ Amato et al. ${ }^{20}$ evaluated different sealing methods and found no significant difference in sealer penetration, despite the lack of standards for evaluating the cross-sections or the amount of sealer applied to each canal. A preferable method has not been described in the literature. ${ }^{8,20,21}$ However, LS has been reported to be better than sonic files and K-files in the study by Kahn et al. ${ }^{7}$ In contrast, this study reported that EC was significantly better than EA in both analyses, and the percentage of sealer penetration by EC and EA were better than LS.

Similarly, others have reported a significantly superior sealer penetration at greater distances $(\mathrm{mm})$ from the apex..$^{3,15,22,23}$ The probable reason for this is that the apical region has fewer dentinal tubules with smaller diameters, more sclerotic dentin, ${ }^{23}$ and a more difficult access for irrigants. Conversely, Generali et al. ${ }^{17}$ reported no difference, probably because the irrigants were activated at $2 \mathrm{~mm}$ from the working length.

Considering irrigation technique, all the $5-\mathrm{mm}$ experimental groups, except NTLS5, presented the best performance for maximum depth sealer penetration analysis. This may have occurred due to the large surface area of the Lentulo spiral, which generates less pressure within the root canal and worse performance compared to manual irrigation.

Among the 2-mm experimental groups, EAEC2 was the best combination when both analyses were considered, probably because of the small surface area added to continuous rotating movement and sonic irrigation.
In endodontics, CLSM is used to evaluate root structure alterations, bacteria, and sealer detection in dentinal tubules. ${ }^{24}$ Rhodamine B isothiocyanate is a fluorescent dye with chemical formula $\mathrm{C}_{29} \mathrm{H}_{30} \mathrm{ClN}_{3} \mathrm{O}_{3} \mathrm{~S}$ frequently used in $\mathrm{CLSM}^{11,25}$ and in leakage studies. ${ }^{26,27}$ Rhodamine has excellent phototophysic properties such as high levels of absorption coefficient and quantum yield. ${ }^{28}$ The specific amount of dye was selected by empirical method $^{25}$ and $0.3 \mathrm{mg} / \mathrm{mL}$ was chosen as the appropriate concentration for endodontic $\mathrm{AH}$ Plus sealer studies, as reported by our pilot study. Rhodamine B isothiocyanate did not interfere in the chemistry of the endodontic sealer. ${ }^{11}$

SEM evaluation has been applied in endodontics to evaluate the sealer penetration in the dentinal tubules. ${ }^{12}$ Cathodoluminescence is a powerful tool in the field of quantum emitters, ${ }^{29}$ in which electrons impacting a luminescent material result in the emission of photons that may present wavelengths in the visible spectrum..$^{30}$ CLSM as well as SEM evaluations allow the measurement of maximum depth and percentage of sealer penetration. SEM is limited to a superficial view. However, with the CLSM method, the overlap of horizontal image sections can hide empty dentinal tubules overestimating sealer penetration. In this study, SEM evaluation was applied instead of CLSM because it is a novel method that demands less time and results in good image quality.

The results of our study indicate a statistical difference in irrigation protocols and between sealer placement devices compared to the control group, because saline is not efficient in removing smear layer. ${ }^{13}$ The percentage area of sealer penetration is probably more clinically relevant than the maximum depth of sealer penetration, for indication endodontic seal quality. ${ }^{15}$

\section{Conclusions}

Sonic irrigant activation improved sealer penetration into the dentinal tubules. When all factors were considered, the 5-mm experimental groups presented the best performance for sealer penetration. 


\section{References}

1. Shokouhinejad N, Sabeti M, Gorjestani H, Saghiri MA, Lotfi M, Hoseini A. Penetration of Epiphany, Epiphany self-etch, and $\mathrm{AH}$ Plus into dentinal tubules: a scanning electron microscopy study. J Endod. 2011;37(9):1316-9. https://doi.org/10.1016/i.joen.2011.05.002

2. Kara Tuncer A, Ünal B. Comparison of sealer penetration using the EndoVac irrigation system and conventional needle root canal irrigation. J Endod. 2014;40(5):613-7. https://doi.org/10.1016/i.joen.2013.11.017

3. Moon YM, Shon WJ, Baek SH, Bae KS, Kum KY, Lee W. Effect of final irrigation regimen on sealer penetration in curved root canals. J Endod. 2010;36(4):732-6. https://doi.org/10.1016/i.joen.2009.12.006

4. Caron G, Nham K, Bronnec F, Machtou P. Effectiveness of different final irrigant activation protocols on smear layer removal in curved canals. J Endod. 2010;36(8):1361-6. https://doi.org/10.1016/i.joen.2010.03.037

5. Mendonça DH, Colucci V, Rached-Junior FJ, Miranda CE, Silva-Sousa YT, Silva SR. Effects of various irrigation/aspi ration protocols on cleaning of flattened root canals. Braz Oral Res. 2015;29(1):1-9. https://doi.org/10.1590/1807-3107BOR-2015.vol29.0082

6. Heling I, Chandler NP. The antimicrobial effect within dentinal tubules of four root canal sealers. J Endod. 1996;22(5):257-9. https://doi.org/10.1016/S0099-2399(06)80144-5

7. Kahn FH, Rosenberg PA, Schertzer L, Korthals $G$, Nguyen PN. An in-vitro evaluation of sealer placement methods. Int Endod J. 1997;30(3):181-6. https://doi.org/10.1111/j.1365-2591.1997.tb00694.x

8. Wiemann AH, Wilcox LR. In vitro evaluation of four methods of sealer placement. J Endod. 1991;17(9):444-7. https://doi.org/10.1016/S0099-2399(07)80134-8

9. Guinesi AS, Faria G, Tanomaru-Filho M, BonettiFilho I. Influence of sealer placement technique on the quality of root canal filling by lateral compaction or single cone. Braz Dent J. 2014;25(2):117-22. https://doi.org/10.1590/0103-6440201302370

10. Chandra SS, Shankar P, Indira R. Depth of penetration of four resin sealers into radicular dentinal tubules: a confocal microscopic study. J Endod. 2012;38(10):1412-6. https://doi.org/10.1016/i.joen.2012.05.017

11. D'Alpino PH, Pereira JC, Svizero NR, Rueggeberg FA, Pashley DH. Use of fluorescent compounds in assessing bonded resin-based restorations: a literature review. J Dent. 2006;34(9):623-34. https://doi.org/10.1016/i.jdent.2005.12.004

12. Kokkas AB, Boutsioukis AC, Vassiliadis LP, Stavrianos $C K$. The influence of the smear layer on dentinal tubule penetration depth by three different root canal sealers: an in vitro study. J Endod. 2004;30(2):100-2. https://doi.org/10.1097/00004770-200402000-00009
13. Zehnder M. Root canal irrigants. J Endod. 2006;32(5):389-98. https://doi.org/10.1016/i.joen.2005.09.014

14. Irala LE, Grazziotin-Soares R, Salles AA, Munari AZ, Pereira JS. Dissolution of bovine pulp tissue in solutions consisting of varying $\mathrm{NaOCl}$ concentrations and combined with EDTA. Braz Oral Res. 2010;24(3):271-6. https://doi.org/10.1590/S1806-83242010000300003

15. Bolles JA, He J, Svoboda KK, Schneiderman E, Glickman GN. Comparison of Vibringe, EndoActivator, and needle irrigation on sealer penetration in extracted human teeth. J Endod. 2013;39(5):708-11. https://doi.org/10.1016/i.joen.2013.01.006

16. Uroz-Torres D, González-Rodríguez MP, FerrerLuque CM. Effectiveness of the EndoActivator System in removing the smear layer after root canal instrumentation. J Endod. 2010;36(2):308-11. https://doi.org/10.1016/i.joen.2009.10.029 PMID:20113797

17. Generali L, Cavani F, Serena V, Pettenati C, Righi E, Bertoldi C. Effect of different irrigation systems on sealer penetration into dentinal tubules. J Endod. 2017;43(4):652-6. https://doi.org/10.1016/i.joen.2016.12.004 PMID:28342477

18. Gu LS, Kim JR, Ling J, Choi KK, Pashley DH, Tay FR. Review of contemporary irrigant agitation techniques and devices. J Endod. 2009;35(6):791-804. https://doi.org/10.1016/i.joen.2009.03.010

19. Balguerie E, van der Sluis L, Vallaeys K, GurgelGeorgelin M, Diemer F. Sealer penetration and adaptation in the dentinal tubules: a scanning electron microscopic study. J Endod. 2011 Nov;37(11):1576-9. https://doi.org/10.1016/i.joen.2011.07.005

20. Amato R, Goldman M, Tenca J, Burk G. A comparison of the efficiency of various delivery methods on sealer distribution. AAB Abstr Papers. 1984;10:119.

21. Hall MC, Clement DJ, Dove SB, Walker WA 3rd. A comparison of sealer placement techniques in curved canals. J Endod. 1996;22(12):638-42. https://doi.org/10.1016/S0099-2399(96)80055-0

22. Kara Tuncer A, Tuncer S. Effect of different final irrigation solutions on dentinal tubule penetration depth and percentage of root canal sealer. J Endod. 2012;38(6):860-3. https://doi.org/10.1016/i.joen.2012.03.008

23. Miör IA, Smith MR, Ferrari M, Mannocci F. The structure of dentine in the apical region of human teeth. Int Endod J. 2001;34(5):346-53 https://doi.org/10.1046/i.1365-2591.2001.00393.x

24. Parmar D, Hauman CH, Leichter JW, McNaughton A, Tompkins GR. Bacterial localization and viability assessment in human ex vivo dentinal tubules by fluorescence confocal laser scanning microscopy. Int Endod J. 2011;44(7):644-51. https://doi.org/10.1111/j.1365-2591.2011.01867.x 
Effectiveness of different final irrigation techniques and placement of endodontic sealer into dentinal tubules

25. Pioch T, Stotz S, Staehle HJ, Duschner H.

Applications of confocal laser scanning microscopy to dental bonding. Adv Dent Res. 1997;11(4):453-61. https://doi.org/10.1177/08959374970110041201

26. de Souza EB, de Amorim CV, Marques JL. Effect of diode laser irradiation on the apical sealing of MTA retrofillings. Braz Oral Res. 2006;20(3):231-4. https://doi.org/10.1590/S1806-83242006000300009

27. Kubo CH, Valera MC, Gomes AP, Mancini MN, Camargo $\mathrm{CH}$. The effect of endodontic materials on the optical density of dyes used in marginal leakage studies. Braz Oral Res. 2008;22(1):25-30. https://doi.org/10.1590/S1806-83242008000100005
28. Zheng $H$, Zhan XQ, Bian QN, Zhang XJ. Advances in modifying fluorescein and rhodamine fluorophores as fluorescent chemosensors. Chem Commun (Camb). 2013 Jan;49(5):429-47. https://doi.org/10.1039/C2CC35997A

29. Kociak M, Zagonel LF. Cathodoluminescence in the scanning transmission electron microscope. Ultramicroscopy. 2016;174:50-69.

30. Coenen T, Brenny BJ, Vesseur EJ, Polman A. Cathodoluminescence microscopy: optical imaging and spectroscopy with deep-subwavelength resolution. Multiscale mechanics of biological, bioinspired, and biomedical materials. MRS Bull. 2015;40(4):359-65. https://doi.org/10.1557/mrs.2015.64. 